\title{
Monitoring developmental trajectories in novel metaphor comprehension in children with ASD: a case study
}

\author{
Melogno S. ${ }^{1}$ - Pinto M.A. ${ }^{1}$ - Di Filippo G. ${ }^{2}$ \\ ${ }^{1}$ Department of Psychology of Developmental Processes and Socialization, "Sapienza" \\ University of Rome, Italy \\ ${ }^{2}$ Department of Psychology, "Niccolò Cusano" Telematic University, Rome, Italy
}

DOI: http://dx.doi.org/10.7358/neur-2017-022-melo

sergio.melogno@uniroma1.it

\section{ABSTRACT}

The study of developmental trajectories in metaphor comprehension has prevailingly addressed typically developing children (TD children, henceforth), and more recently, also children with Autism Spectrum Disorder (ASD, henceforth). Monitoring these trajectories longitudinally illuminates potentialities and residual weaknesses in children having had difficulties in handling figurative language. The present study describes the case of a child with ASD, M.M. (a pseudonym) who received a specific intervention when he was 8,10 to improve sensory metaphor comprehension. Afterwards, his capability to explain physico-psychological metaphors, which are more complex, was monitored across a 5-year span. During this interval, M.M was assessed three times at approximately 18 months distance, and compared to a group of TD children matched by age, school grade, number and dates of assessment. The results at a test measuring physico-psychological metaphors are analysed. Beyond quantitative differences in performance, differences in the developmental trajectories of M.M. and the TD children are outlined. Some implications for clinical assessment and intervention with children with ASD are also pointed out.

Keywords: Developmental trajectories; Metaphor comprehension; Children; Autism Spectrum Disorder; Longitudinal monitoring. 


\section{INTRODUCTION}

In contrast with the first studies (Happé, 1993, 1995), in a recent meta-analysis by Kalandadze, Norbury, Naerland, and Naess (2016), it has been argued that the deficit of figurative language comprehension in individuals with ASD is neither specific to autism nor generalised to all individuals with autism. This deficit would affect mainly some subgroups of individuals with ASD presenting specific cognitive profiles characterised by particular peaks and dips. In some studies, weaknesses have been identified with linguistic impairments (Gernsbacher \& Pripas-Kapit, 2012; Norbury, 2005) or with Theory of Mind deficits (Dennis, Lazenby, \& Lockyer, 2001; Happé, 1993, Martin \& McDonald, 2004), and executive functioning problems (Mashal \& Kasirer, 2011; Kasirer \& Mashal, 2016), or else, with Weak Central Coherence in information processing (Rundblad \& Annaz, 2010; for a review, see Vulchanova, Saldaña, Chahboun, \& Vulchanov, 2015). Therefore, results appear extremely heterogeneous and do not allow any reliable conclusion (Kalandadze et al., 2016). This variability can also be found in the subarea of metaphor comprehension in children with ASD (Melogno, Pinto, \& Levi, 2012).

In its prototypical form, "X is Y", metaphor is composed by two terms, the first is called "tenor" and the second, "vehicle" (Richards, 1936): e.g. "A teacher is an encyclopedia". As these terms pertain to two different domains, namely, the domain of human beings and that of physical objects, their association generates a semantic conflict. It is precisely this conflict that has to be solved by detecting a "common ground" between the two terms. In the above example, the "common ground" refers to the semantic features shared by both teacher and encyclopedia, namely, the transmission of knowledge.

While in typical development several studies have explored the comprehension of different typologies of metaphors, based, for example, on the distinction between sensory and physico-psychological (Winner, 1998), only a few studies on children with ASD have acknowledged these distinctions (Melogno, D’Ardia, Pinto, \& Levi, 2012). Sensory metaphors associate two terms both pertaining to a concrete domain (e.g.: "the sun is an orange"), whereas physicopsychological metaphors associate two different domains, one pertaining to concrete objects, and the other, to human beings (e.g.: "A teacher is an encyclopedia"). From a developmental point of view, many studies (Keil, 1986; Vosniadou, Ortony, Reynolds, \& Wilson, 1984; Winner, 1998) indicate that TD children are able to understand and even explain sensory metaphors since preschool age, whereas they encounter more difficulties in explaining physico-psychological metaphors. This ability increasingly improves until adolescence (Declerq, Baltazart, \& Didon, 2010; Johnson \& Pascual Leone, 1989; Winner, 1998). For children with ASD it is even harder to establish whether the issue is metaphor per se or only 
some typologies of metaphor as a function of semantic complexity, and also whether difficulties remain constant or evolve across time.

Some researchers have recently tried to study these trajectories until adulthood. For instance, Rundblad and Annaz (2010), in a study on 5- to 13 year-old children with ASD, showed that there were two different developmental trajectories, one for metaphor and the other for metonymy. Metonymy proved easier than metaphor as in TD children, although slightly delayed. On the contrary, metaphor showed a more delayed development and never reached the optimal level. Kasirer and Mashal (2016), using a multiple choice task with children with ASD from 9 to 16 years, found lower performances in lexicalised metaphor comprehension than in typically developing controls, but no difference in novel metaphors ${ }^{1}$. The same Authors (Kasirer \& Mashal, 2014) conducted a study on novel and lexicalised metaphors, in both comprehension and production, with adults with ASD compared to a control group. No differences were found in comprehension, but in production the group with ASD outperformed the control group. Gold and colleagues (Gold, Faust, \& Goldstein, 2010) found that individuals with Asperger syndrome had longer reaction times than the typically developed controls at both lexicalised and novel metaphors, and different brain activation patterns. This suggests that, beyond accuracy, the mental processes used by individuals with ASD are atypical.

Currently, there are several pending issues about the extent to which it is possible to improve metaphor comprehension, with or without intervention. Some studies show that it is possible to teach strategies to cope with the difficulties posed by metaphors with children from 5 to 15 years (Mashal \& Kasirer, 2011; Persicke, Tarbox, Ranick, \& St. Clair, 2012). Adapting a procedure used in brain lesions rehabilitation (Lundgren, Brownel, Soma, \& Cayer-Meade, 2006), Mashal and Kasirer (2011) taught children with ASD to use thinking maps as a tool to analyse metaphorical sentences. Persicke et al. (2012) devised a methodology to facilitate children with ASD in analysing metaphors embedded in stories.

In a case study (XXXXX), we investigated about the effects of a treatment implemented with a child with ASD (8, 10 years), called M.M. This child had a Verbal IQ of 115 (Full IQ: 110; Performance IQ: 103; Wechsler, 2003). His grammatical and lexical competencies were also within norms, as assessed, respectively, by Test of Reception of Grammar (TROG 2; Bishop, 2003: standard score: 107) and Peabody Picture Vocabulary Test (PPVT; Dunn \& Dunn, 1981;

\footnotetext{
${ }^{1}$ Novel metaphors differ from lexicalised metaphors to the extent that the former are an original product, never heard before, while the latter are currently in use.
} 
standard score: 115). In metaphor comprehension, instead, M.M.' level was under that of 6 year-old children. In this study, at time 0, M.M.'s metaphor comprehension was assessed with a test based on sensory metaphors (Pinto, Melogno, \& Iliceto, 2008). M.M. then received a baseline treatment focussed on Theory of Mind (involving emotion recognition and comprehension, and mental states inference), after which his metaphor comprehension was assessed again (time 1). An experimental treatment was then implemented. Immediately after (time 2) and four months later (time 3), M.M. was assessed again.

The experimental treatment ( 8 sessions, 45-60 minutes each) consisted in teaching two strategies to cope with the difficulties posed by sensory metaphors, presented in the classical form " $\mathrm{X}$ is $\mathrm{Y}$ ". With the first strategy, called " $X$ is $Y$ heuristic", the child was suggested to inhibit his literal interpretation by changing the metaphor into a simile ("X is like $\mathrm{Y}$ "). With the second strategy, called "comparative strategy", M.M. was taught to use thinking maps in search for semantic similarities between " $X$ " and "Y". For instance, for the metaphorical sentence "Skyscrapers are the city's giraffes", M.M. had to: a) transform the sentence into a simile "'Skyscrapers are like city's giraffes"); b) identify relevant features in both "skyscrapers" ("building", "city", "very high") and "giraffes" ("animal", "long neck", "savannah", "very high"; c) discard irrelevant features and come to a plausible common ground (In this case, the exceptional height of both giraffe and skyscraper). Before the baseline treatment (time 0 ), the performance at sensory metaphors was: $\mathrm{z}=$ 2,13 (t score: 29). After this treatment (time 1), it was: $\mathrm{z}=-1,95$ ( $\mathrm{t}$ score: 30 ); after the experimental treatment (time 2 ), it was $\mathrm{z}=3,14$ ( $\mathrm{t}$ score: 81 ), and at the follow-up (time 3), it was $z=3,87$ ( $\mathrm{t}$ score: 89 ). ${ }^{2}$ The standard error measurement showed a significant difference between performances at time 1 and time $2\left(\mathrm{~S}_{\mathrm{e}}: 4,6764 ; \mathrm{p}<0,05\right)$. Therefore, after the experimental treatment, performances significantly increased and nearly reached the ceiling. At time 3, there was a further improvement, although not significant.

The aim of the present study was to illustrate the monitoring of the metaphor comprehension process in M.M. after the intervention on sensory metaphors, but with a more complex type of metaphors, namely, the physicopsychological ones, and, this time, without intervention. The current study has, therefore, an exploratory character.

${ }^{2}$ The child's performance was compared to that of 6 year-old children of the normative sample of the metaphor comprehension test used in this study (Junior MCT; Pinto et al., 2008). 


\section{METHOD}

We monitored the physico-psychological metaphor comprehension process in M.M. in two ways, with a standardised assessement and a parents' interview. We assessed the child at three different times, when he was, respectively 10,9, 12,5 and 14. During this interval, no specific treatment nor other types of interventions were implemented. M.M.'s performances were compared to those of six TD children, matched by age ( \pm 4 months), school grade ${ }^{3}$, number of assessments in the same interval, at the same moments. In addition, before each assessment, we had a short interview (See Appendix) with parents to check the evolution of metaphorical language on the basis of reported behavior. Due to space constraints, in the present study we will limit ourselves to the results of the assessment.

\subsection{Participant}

M.M. received a diagnosis of Asperger Syndrome when he was 8,10, based on DSM IV-TR's criteria (APA, 2000). The diagnosis of ASD was confirmed, based on DSM 5's criteria (APA, 2013).

M.M. was a child with fluent and erudite language abilities but evident difficulties in social interaction, especially with peers, and behavioural rigidity. $\mathrm{He}$ his reported by his parents as a child tending to interpret language too literally. For instance, when M.M.'s teacher gave one of his classmates the nickname "spinning top", M.M. started to look around in the classroom, in search for a real spinning top. Tendency towards excessive literality was confirmed at the first standardised assessment, at time 0 of the study described in the Introduction.

At the WISC IV (Wechsler, 2003) his relatively high performance was confirmed (Verbal Comprehension: 120; Perceptual Reasonment: 124; Working Memory:151; Processing Speed: 103). M.M.'s Full IQ was 132, M.M.'s General Ability Index was 125. M.M.'s lexical competencies, as measured by PPVT (Dunn \& Dunn, 1981), were adequate (standard score: 128; normative range: $10,7-11,6)$ as well as his grammatical competencies, as measured by TROG 2 (Bishop, 2003; standard score: 119).

M.M.'s Theory of mind was further explored with NEPSY II battery (Developmental Neuropsychological Assessment; Korkman, Kirk, \& Kemp, 2007), and was at the expected level (standard score: 8) while the ability to recognize emotional affect was borderline (standard score: 7 ).

${ }^{3}$ The matching for school grade was based on reading comprehension, as assessed by school teachers. 


\subsection{Metaphor Comprehension Assessment}

To assess metaphor comprehension, we used the Metaphor Comprehension Test (MCT; Pinto, Melogno, \& Iliceto, 2006), a test validated for an Italianspeaking population (9-14 years) that assesses the capability to explain novel physico-psychological metaphors. The MCT is composed of 12 metaphorical sentences, such as "The guardian of the prison is a rock". Questions and answers are purely verbal. The coding system is based on qualitative levels, transformed into a four-step scale.

- A score of 0 is assigned when the child declares he/she just does not know or refuses the possibility of using words metaphorically or interprets the metaphor literally.

- A score of 1 is assigned when the child provides a common ground between tenor and vehicle on a physical basis (e.g.: "It (the guardian) doesn't move, like a rock)

- A score of 2 is assigned when the child provides a more elaborated common ground where psychological features are explicitly indicated (e.g: "the guardian is stubborn, he doesn't allow to visit the prisoners").

- A score of 3 is assigned when the psychological features that justify the common ground are further refined (e.g: "The guardian is hard-hearted, insensitive, inflexible, etc.).

The maximum score of the MCT is 36 .

Raw scores can be converted into $t$ scores, which are subdivided into five ranges, from deficitary $(\leq 30)$ to inferior-average $(>30-\leq 40)$, average $(>40-\leq$ $60)$, superior-average $(<60 \leq 70)$, superior $(>70)$.

MCT has high reliability (Cronbach'alpha: .70), high test-retest correlations: $\mathrm{r}-\mathrm{tt}: .83$, and high interrater agreement (Cohen's K: 9-10 y: .75; 11 y: .74; 12 y: .67; 13 y: .81).

\section{RESULTS}

Table 1 presents the raw and the t scores of the MCT from time 1 to time 3 in M.M and the six TD children. 
Table 1. Raw and tscores at the MCT for M.M. and the typically-developing children

\begin{tabular}{|c|c|c|c|c|c|c|}
\hline \multirow{2}{*}{$\begin{array}{l}\text { Total } \\
\text { MCT }\end{array}$} & \multicolumn{2}{|c|}{ Time 1} & \multicolumn{2}{|c|}{ Time 2} & \multicolumn{2}{|c|}{ Time 3} \\
\hline & Raw score? & T score & Raw score 1 & T score & Raw score & T score \\
\hline M.M. & 5 & 34 & 5 & 27 & 14 & 40 \\
\hline Child 1 & 14 & 53 & 21 & 58 & 24 & 60 \\
\hline Child 2 & 15 & 56 & 18 & 52 & 24 & 60 \\
\hline Child 3 & 15 & 56 & 23 & 62 & 26 & 64 \\
\hline Child 4 & 12 & 49 & 19 & 54 & 21 & 54 \\
\hline Child 5 & 13 & 51 & 22 & 60 & 34 & 60 \\
\hline Child 6 & 13 & 51 & 19 & 54 & 26 & 64 \\
\hline
\end{tabular}

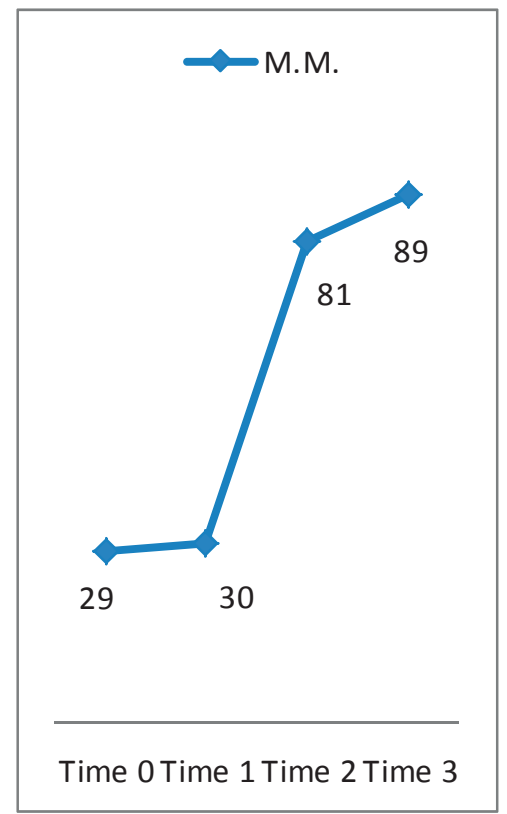

Figure 1. M.M.'s developmental 
M.M.'s level at the MCT was inferior-average at time 1, deficitary at time 2 , and then again inferior-average at time 3 , although at the border with the average level. TD children started at a level very close to M.M.'s final level, and then maintained their average level across time.

Figure 1 shows M.M.'s developmental trajectory in XXXX study, while Figure 2 shows both M.M.'s and the controls' developmental trajectory in the present study.

Table 2 shows the distribution of the answers in the above-described 4step scale. At time 1, the majority of M.M.'s answers were at the lowest level $(58,3 \%)$, followed by a consistent percentage of level 1 answers (41,7\%). At time 2 , the distribution of answers remained unchanged. At time 3, level 0 answers decreased $(33,3 \%)$, and, for the first time, level 2 and 3 answers appeared (respectively, $25 \%$ and 16,7\%). At time 1, the majority of TD children's answers were at level 1 , with very low percentages of level 0 and 2, and no level 3. At time 2 and 3, level 0 answers disappeared with a clear improvement of level 2 and 3 answers' percentages.

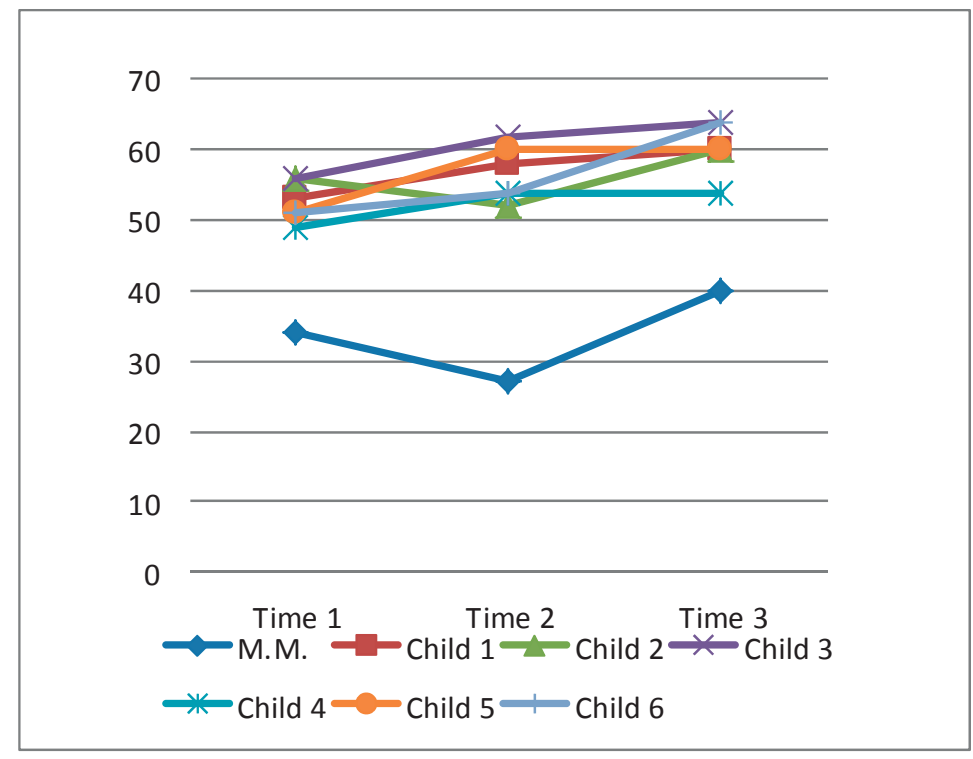

Figure 2. M.M.'s and controls' developmental trajectory in the present study trajectory (XXXX study) 


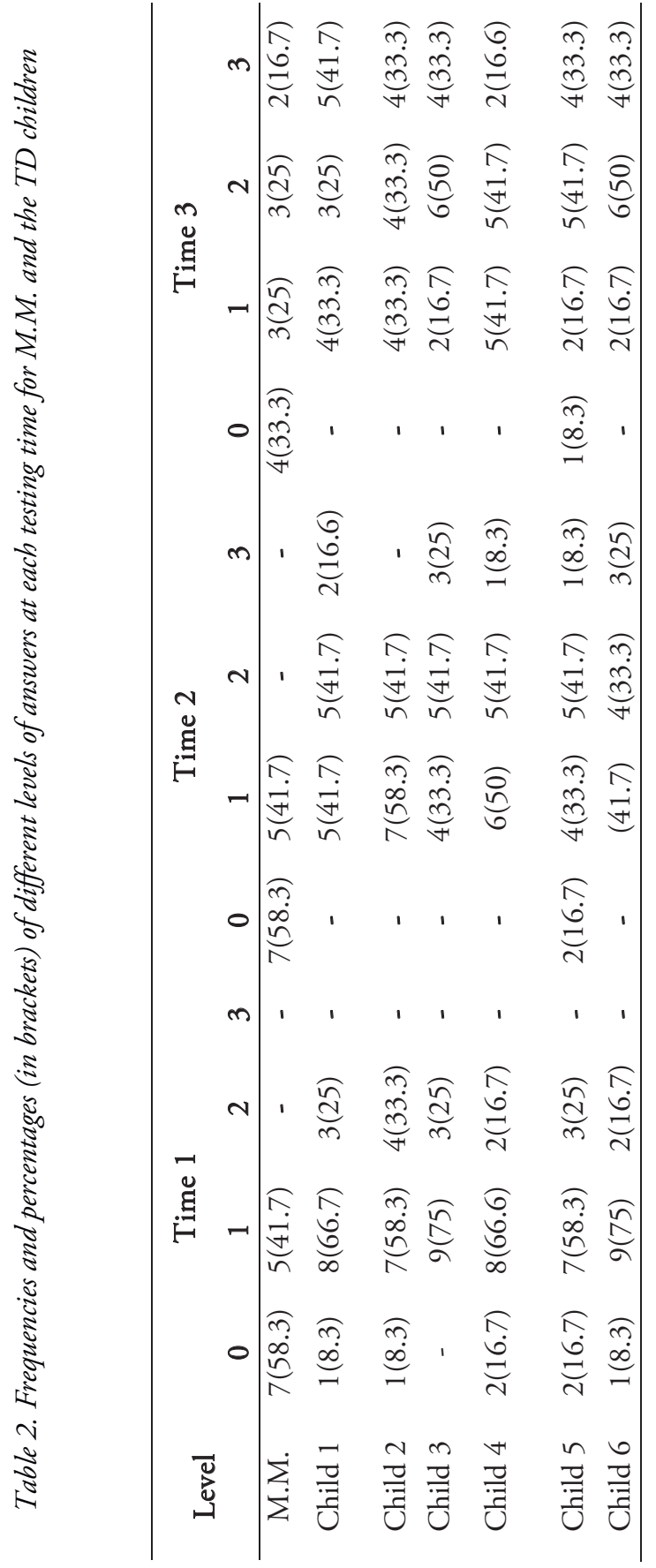




\section{DISCUSSION}

This study presented the monitoring of metaphor comprehension in a child with ASD from the age of 10, 9 to 14, an interval when remarkable advances in this capability are attested in typical development (Winner, 1998). When M.M.' was 8, 10 years-old, severe difficulties could be noted in all forms of non literal usages. At that age, his comprehension of sensory metaphors was deficitary (XXXX). M.M. received a short but intensive treatment, focussed on sensory metaphors and supported by an explicit teaching of strategies. After this treatment, his performances considerably improved and this improvement was stable at a follow-up assessment, four months later (XXXX).

When M.M. was older, his metaphor comprehension was explored with a test that assesses physico-psychological metaphors at three different moments. M.M.'s developmental trajectory was compared to that of a small group of TD children matched by age, school grade, number and dates of testing. The TD children's raw scores gradually increased and were positioned at an average level at all testing times. M.M.'s raw scores, instead, started poorly and then showed a sudden increase at the last assessment but remained under average level at all testing times. Therefore, M.M.'s evolution was slower than his mates', although his starting point was not deficitary, differently from what happened with sensory metaphors, some years before.

On qualitative grounds, we would like to point out some aspects that seem distinctive of M.M.'s approach to physico-psychological metaphors. First of all, refusals were totally absent in his protocols, whereas this type of answer was dominant when he was presented with sensory metaphors (XXXX). Moreover, these refusals were stressed by such strong expressions as: "It's impossible; it just can't be" (Jnr MCT's item: "The moon is a bulb"). Therefore, when he was 8,10, M.M. treated metaphors as if they were "impossible utterances". At age 14, he seemed to acknowledge new linguistic norms, also emphatically asserted, according to which a metaphorical sentence is acceptable only on figurative grounds. "By all means, this must be intended in a figurative sense" (MCT's item: "The prison guardian is a rock"). This might be due to formal teaching of figurative language at school that both M.M. and the controls received, as attested by the interviews (See Appendix, question 5). M.M. gave a high-level answer to this item: "The prison guardian is like a rock because he treats people harshly". It is worth noting that the child spontaneously used the connective "is like" he had been taught during the intervention on sensory metaphors ("X is Y heuristic") when he was 9, and that no typically developing child ever used in any item of the test.

On the other hand, in some items M.M. spontaneously retrieved the meanings of lexicalised metaphors, which might have interfered with the explanation of novel metaphors. For instance, for the item: "That man is a 
volcano", M.M. answered: "A volcano of ideas! This, we can say it, but I don't know if it applies to this case". Therefore, M.M. acknowledged the legitimacy of the association between "volcano" and "ideas", which is a conventionalized one but he did not take a step further to link the meanings of this expression to those of the item of the test. Another example is the item "My sister is a butterfly". At T1 and T2, M.M. gave the same explanation, phrased in identical terms: "My sister has a coloured dress", where the ground was based on a physical and static feature, colour in this case. At T3, M.M. switched to a dynamic feature: "it goes here and there, where it wants it wanders, it runs away from home, so I guess it is not the appropriate meaning". However, M.M. did not link this dynamic feature of the vehicle ("butterfly") to the characteristics of the tenor ("sister"), and he moved to another semantic association, that between "wandering" and "running away from home", which was probably more familiar to him.

In general terms, the identification of a common ground between tenor and vehicle in physico-psychological metaphors requires more complex operations than in sensory metaphors. In addition to identifying common features between tenor and vehicle it is also necessary to adjust these features to the characteristics of the tenor. This adjustment, in turn, requires to inhibit some characteristics as irrelevant and then switch from the meanings selected as relevant to novel meanings (Johnson \& Pascual Leone, 1989; Rubio Fernandez, 2007). Furthermore, explaining physico-psychological metaphors presupposes a certain capability to handle psychological knowledge and mental lexicon, which is not required with sensory metaphors (Baron-Cohen, Golan, Wheelwright, Granader \& Yill, 2010).

Overall, M.M.'s developmental trajectory suggests that metaphor is not in itself an issue for him. After a delayed start, M.M rapidly reaches the highest level in sensory metaphor comprehension thanks to an intervention entirely focussed on this type of metaphor. However, with physico-psychological metaphors and without intervention, M.M.'s evolution slowly reaches a performance just under the expected level at the age of 14 .

This study has two main limitations. The first is that the assessment addressed only the prototypical form of metaphors, "X is $Y$ ", without considering other forms of metaphorical usages. The second limitation regards the purely verbal modality chosen to assess metaphor comprehension, which might have underestimated children's comprehension.

This study also has implications for clinical assessment and intervention. First of all, children as M.M. do not reveal their weaknesses in figurative language usages through their Verbal IQ or Verbal Comprehension Index, nor through their lexical or grammatical competencies, which might be adequate. If we consider the relevance of handling figurative usages appropriately in everyday communication (Balconi, 2008), it is worth devoting a special place to these aspects of communicative competence in assessment. Secondly, these children 
might be able to explain sensory metaphors even at the highest level, although with some intervention and with relative delay compared to TD children but they might lag behind their mates with physico-psychological metaphors. Therefore, assessment must be cautious in drawing conclusions about metaphor comprehension without taking into account the considerable differences in cognitive load related to different typologies of metaphor. Thirdly, we may wonder whether the intervention to improve metaphor comprehension must address sensory and physico-psychological metaphors at different times in development or in combination at a later stage. Some preliminary results (Melogno, Pinto, \& Di Filippo, 2017) would suggest that this combination can yield significant improvements, which let us think that, in this area, treatment can accelerate spontaneous development, at least to a certain extent.

\section{REFERENCES}

American Psychiatric Association (2000). Diagnostic and Statistical Manual of Mental Disorders (4 ${ }^{\text {th }}$ Edn) TextRevision. Washington, DC: Author.

American Psychiatric Association. (2013). Diagnostic and Statistical Manual of Mental Disorders ( $5^{\text {th }}$ Edn). Arlington, VA: American Psychiatric Publishing.

Balconi, M. (2008). Neuropsicologia della comunicazione. Milano: Springer.

Baron-Cohen, S., Golan, O., Wheelwright, S., Granader, Y., \& Yill, J. (2010). Emotion Word Comprehension from 4 to 16 Years Old: A Developmental Survey. Frontiers in Evolutionary Neuroscience, 2(109), 1-8.

Bishop, D.M. (2003). Test for Reception of Grammar. Version 2 (TROG-2). London: Pearson Assessment; (Suraniti, S., Ferri, R., \& Neri, V., eds, Italian Edn. Firenze: Giunti OS, 2011).

Declercq, C., Baltazart, V., \& Didon, D. (2010). Les nuagessont un troupeau de moutons: à quel âge les enfants comprennent-ilsqu'il n'y a pas de moutons dans le ciel? Canadian Journal of Experimental Psychology, 64(2), 142-152.

Dennis, M., Lazenby, A., \& Lockyer, L. (2001). Inferential language in highfunctioning children with autism. Journal of Autism and Developmental Disorders, 31(1), 47-54.

Dunn, L.M., \& Dunn, L.M. (1981). Peabody Picture Vocabulary Test. Circle Pines, MN: American Guidance Service; (Stella, G., Pizzoli, C. and Tressoldi, P.E. Peabody: Test di Vocabolario Ricettivo, Italian Edn. Torino: Omega, 2000). 
Gernsbacher, M. A., \& Pripas-Kapit, S. R. (2012). Who's Missing the Point? A Commentary on Claims that Autistic Persons Have a Specific Deficit in Figurative Language Comprehension. Metaphor and Symbolic Activity, 27(1), 93-105.

Gold, R., Faust, M., \& Goldstein, A. (2010). Semantic integration during metaphor comprehension in Asperger syndrome. Brain and Language, 113(3), 124-134.

Happé, F. (1993). Communicative competence and theory of mind in autism: A test of relevance theory. Cognition, 48(2), 101-119.

Happé, F. (1995). Understanding minds and metaphors: insight from the study of figurative language in autism. Metaphor and Symbolic Activity, 10(4), 275-295.

Johnson, J., \& Pascual Leone, J. (1989). Development Levels of Processing in Metaphor Interpretation. Journal of Experimental Child Psychology, 48(1), 1-31.

Kalandadze, T., Norbury, C., Nærland, T., \& Næss K-A. B. (2016). Figurative language comprehension in individuals with autism spectrum disorder: $\mathrm{A}$ meta-analytic review. Autism. 1-19.

Kasirer, A., \& Mashal, N. (2014). Verbal creativity in autism: comprehension and generation of metaphorical language in high-functioning autism spectrum disorder and typical development. Frontiers in Human Neuroscience, 8, 615.

Kasirer, A., \& Mashal, N. (2016). Comprehension and generation of metaphors by children with autism spectrum disorder. Research in Autism Spectrum Disorders, 32(1), 53-63.

Keil, F.C. (1986). Conceptual domains and and the acquisition of metaphor. Cognitive Development, 1(1), 73-96.

Korkman, M., Kirk, U., \& Kemp, S. (2007). NEPSY II: A developmental neuropsychological assessment. San Antonio, TX: The Psychological Corporation.

Lundgren, K., Brownel, H., Soma, R., \& Cayer-Meade, C. (2006). A Metaphor comprehension intervention for patients with right hemisphere brain damage: a pilot study. Brain and Language, 99(1-2), 60-70.

Martin, I., \& McDonald, S. (2004). An exploration of causes of non-literal problems in individuals with Asperger Syndrome. Journal of Autism and Developmental Disorders, 34(3), 311-328.

Mashal, N., \& Kasirer, A. (2011). Thinking maps enhance metaphoric competence in children with autism and learning disabilities. Research in Developmental Disabilities, 32(6), 2045-2054.

Melogno, S., D'Ardia, C., Pinto, M. A., \& Levi, G. (2012). Explaining metaphors in high functioning Autism Spectrum Disorder children: A brief report. Research in Autism Spectrum Disorders, 6(2), 683-689. 
Melogno, S., Pinto, M. A., \& Levi, G. (2012). Metaphor and metonymy comprehension in ASD children: A critical review from a developmental perspective. Research in Autism Spectrum Disorders, 8, 1289-1296.

Melogno, S., Pinto M.A., \& Di Filippo G. (2017). Sensory and PhysicoPsychological Metaphor Comprehension in Children with ASD: A Preliminary Study on the Outcomes of a Treatment. Brain Sciences, 7, 85.

Norbury, C. F. (2005). The relationship between theory of mind and metaphor: Evidence from children with language impairment and autistic spectrum disorder. British Journal of Developmental Psychology, 23(3), 383-399.

Persicke, A., Tarbox, J., Ranick, J., \& St. Clair, M. (2012). Establishing metaphorical reasoning in children with autism. Research in Autism Spectrum Disorders, 6(2), 913-920.

Pinto, M.A., Melogno, S., \& Iliceto, P. (2006). TCM. Test di comprensione delle metafore. Scuola elementare e media. Roma: Carocci.

Pinto, M.A., Melogno, S., \& Iliceto, P. (2008). TCM Junior. Test di comprensione delle metafore. Scuola dell'Infanzia e Scuola primaria. Roma: Carocci.

Richards, I. A. (1936). The Philosophy of Rhetoric. Oxford: Oxford University Press.

Rubio Fernandez, P. (2007). Suppression in metaphor interpretation: differences between meaning selection and meaning construction. Journal of Semantics, 24(4), 345-371.

Rundblad, G., \& Annaz, D. (2010). The atypical development of metaphor and metonymy comprehension in children with autism. Autism, 14, $29-47$.

Vosniadou, S., Ortony, A., Reynolds, R. E., \& Wilson, P. T. (1984). Sources of difficulties in the young child's understanding of metaphorical language. Child Development, 55(4), 1588-1606.

Vulchanova, M., Saldaña, D., Chahboun, S., \& Vulchanov, V. (2015). Figurative language processing in atipical populations: the ASD perspective. Frontiers in Human Neuroscience, 9(24), 1-11.

Wechsler, D. (2003). Wechsler Intelligence Scale for Children (4th ed.) San Antonio, TX: Harcourt Assessment

Winner, E. (1998). The Point of the Words. Harvard: Harvard University Press. 
APPENDIX

Parents' interview to monitor their children's metaphorical language comprehension (school age)

1. Does your child tend towards literal interpretation of discourse? For instance, if someone says "I'll be coming in a minute", does he/she show perplex if the actual time elapsed is longer? Can you recall any example of this kind in recent times?

2. If one refers to an object with an unusual word, does your child understand the meaning appropriately? For instance, if someone refers to a void swimming-pool by calling it "It's a plate with no soup inside", would he/she understand that it is just a different way to call the same thing? Can you recall any example of this kind in recent times?

3. When a word is used with a meaning different from the usual one, does your child understand it appropriately? For instance, if one says that a kind person is "sweet", does he/she understand the intended meaning? Can you recall any example of this kind in recent times?

4. Did your child, in recent times, use such non literal expressions as "to lose face", that he/she might have learned at school or with his/her mates? Does he/she use unconventional expressions that he/she cannot have heard from other people? Can you recall any example of this kind?

5. Do you know whether figurative language (the interviewer provides the parents with some examples) have been the object of explicit teaching at school, recently? If so, can you give any example? 
